Published by Al-Nahrain College of Medicine P-ISSN 1681-6579

E-ISSN 2224-4719

Email: iraqijms@colmed-alnahrain.edu.iq

http://www.colmed-alnahrain.edu.iq

http://www.iraqijms.net

\title{
Allergic Fungal Rhinosinusitis in Patients with Nasal Polyposis
}

\author{
Jaafer M.K. Al-Hassani ${ }^{1}$ FICMS (ENT), Dawood S. Hussein ${ }^{2}$ FICMS (ENT), Abdul Kareem H. Dabi ${ }^{3}$ \\ FICMS (ENT)
}

\footnotetext{
${ }^{1}$ Dept. of Surgery, College of Medicine, Al-Nahrain University, Baghdad, Iraq, ${ }^{2}$ Dept. of Surgery, Al-Imamein AlKadhimein Medical City, Baghdad, Iraq, ${ }^{3}$ Dept. of Surgery, Al-Kindy Hospital, Baghdad, Iraq
}

\begin{abstract}
Background Nasal polyposis and chronic rhinosinusitis is much debated subject. Generally speaking, nasal polyposis should probably be regarded as one form of chronic inflammation in the nose and sinuses, which is indeed part of the spectrum of chronic rhinosinusitis. Nasal polyposis is the ultimate form of inflammation for unknown reasons; polyps preferentially develop in subtypes of inflammatory diseases. Allergic fungal rhinosinusitis (AFRS) is defined the consequence of immunocompetent patient whenever there is allergy to fungus.

Objective To determine the frequency of allergic fungal rhinosinusitis among patients having nasal polyposis.

Methods A prospective study of 60 selected patients with nasal polyposis was studied at Al-Imamein AlKadhimein Medical City. After thorough history and full ENT examination, all patients sent for computed tomography (CT) scan of the nose and paranasal sinuses. Patients who needed surgical treatment, the specimens were sent for histopathological analysis to identify the fungi. The diagnosis of allergic fungal sinusitis was based on analysis of clinical, radiological, and laboratory investigations.

Results The mean age was $(41.3 \pm 13.7)$ years; male to female ratio was $(1.7: 1)$. Both nasal obstruction 54 $(90 \%)$ and nasal discharge $51(85 \%)$ were the commonest clinical presentation. CT scans opacities were found in all 60 patients (100\%). Fungal elements were detected by histopathological study in $7(11.7 \%)$ of them.
\end{abstract}

Conclusion Allergic fungal rhinosinusitis is a significant cause of nasal polyposis.

Keywords Allergy, fungal infection, nasal polyposis.

DOI: $10.22578 /$ IJMS.14.4.11

List of abbreviation: ESS = endoscopic sinus surgery, $\mathrm{CT}=$ Computed tomography, CRS = Chronic rhinosinusitis, AFRS = Allergic fungal rhinosinusitis, $\mathrm{ABPA}=$ Allergic bronchopulmonary aspergillosis, EMCRS = Eosinophilic mucin chronic rhinosinusitis, H\&E = hematoxylineosin, $\mathrm{MRI}=$ Magnetic resonance imaging, $\mathrm{CN}=$ Cranial nerve

\section{Introduction}

$\mathrm{N}$ asal polyps are always associated with paranasal sinus pathology. There is hyperplasia of the maxillary mucous membrane and the ethmoidal cells are filled with polypoid mucous membrane. This pathology may not necessarily result in symptoms, but it can cause a feeling of congestion and may also increase the tendency to bacterial infection, especially following a common cold. When polyps develop in children, it can cause widening of the ethmoidal cells, and flattening and broadening of the nasal bridge (frog nose) ${ }^{(1)}$. Patients with severe nasal polyposis and blood eosinophilia often have, or will develop, asthma (30 percent) and/or non-steroidal antiinflammatory drugs (NSAID) intolerance (15\%). Most patients develop asthma before polyps. When ingestion of NSAID within minutes to a few hours has resulted in rhinitis, asthma, skin itching or urticaria, then the diagnosis is made. 
In case of doubt, a challenge test with acetylsalicylic acid may be necessary ${ }^{(1)}$. Large polyps can be identified by simple rhinoscopy. Rigid scope is the preferred examination, as it can diagnose small polyps in the middle meatus and give a superior assessment of the extent of the disease and of anatomical abnormalities $^{(1)}$ (Table 1$)$.

Table 1. Endoscopic staging of nasal polyposis (1)

\begin{tabular}{lc}
\hline Endoscopic appearace & Score \\
\hline No polyp & 0 \\
Restricted to middle meatus & 1 \\
Below middle turbinate & 2 \\
Massive polyposis & 3 \\
\hline
\end{tabular}

Computerized tomography (CT) scan of the nose and paranasal sinuses gives an excellent demonstration of the anatomy and pathology. It is indicated in all cases before endoscopic surgery. In addition, it is used for staging of the disease $^{(1)}$ (Table 2).

Table 2. CT scan staging of nasal polyposis ${ }^{(1)}$

\begin{tabular}{lll}
\hline Sinus site & Right & Left \\
& & \\
\hline Maxillary & $0-2$ & $0-2$ \\
Anterior ethmoid & $0-2$ & $0-2$ \\
Posterior ethmoid & $0-2$ & $0-2$ \\
Sphenoid & $0-2$ & $0-2$ \\
Frontal & $0-2$ & $0-2$ \\
Ostiomeatal complex & $0-2$ & $0-2$ \\
\hline Total & $0-12$ & $0-12$ \\
\hline
\end{tabular}

$0=$ no opacity; $1=$ some opacity; 2 = total opacity

Fungi can cause both acute and CRS disorders, and can occur as either tissue-invasive or noninvasive conditions as delineated by deShazo and colleagues, $1997^{(2)}$. Invasive disorders include: (i) Acute fulminate necrotizing form is the classic fungal infection epitomized by 'Mucormycosis'. Patients typically are immunosuppressed, and the infection leads to widespread facial and paranasal tissue necrosis that has high morbidity and mortality, (ii) Chronic invasive fungal rhinosinusitis. It has often been reported in diabetics and commonly leads to periorbital tissue invasion and the 'orbital apex syndrome. Surgical resection and systemic antifungal drugs are required, but the infection may recur and is difficult to treat and (iii) Granulomatous invasive fungal sinusitis, indolent fungal sinusitis and primary paranasal granuloma ${ }^{(2)}$. Here, the fungal infection is more localized to the superficial sinus mucosa and is well contained within a robust granulomatous inflammatory process. Sinus mucosal resection may be curative, but systemic antifungal drugs are commonly used postoperatively to assure complete resolution of fungal infection once the histopathological diagnosis is available ${ }^{(2)}$. The second type is noninvasive fungal rhinosinusitis. This includes fungal ball 'sinus mycetoma' and allergic fungal rhinosinusitis (AFRS). (i) Fungal ball is a multitude of fungal hyphae that compressed into a thick exudate within a sinus lumen. (ii) Allergic fungal rhinosinusitis. It is defined as an immunocompetent patient with an allergy to fungus. Since initial publications, approximately $7 \%$ of all chronic rhinosinusitis cases requiring surgery have been diagnosed as AFRS; the fungi, which are the cause of the hypersensitivity reside in the mucin and provide continued stimulation (2).

This study designed to determine the frequency of AFRS among patients having nasal polyposis.

\section{Methods}

A prospective study of 60 selected patients was conducted in the ENT Department at AlImamein A-Kadhimein Medical City, Baghdad from December 2012 to December 2013. All patients were with nasal polyposis between 11 to 60 years old. Immuncompromised patients were excluded from this study.

Thorough history, full ENT examination including nasal endoscopy under local anesthesia using $0^{\circ}$ and $30^{\circ}$ rigid Hopkins 
telescope, radiological examination and laboratory investigations were done to all of them.

CT scans of the nose and paranasal sinuses axial and coronal $(3 \mathrm{~mm})$ slice, over the osteomeatal complex, revealed a mass in the nasal cavity, osteomeatal complex obstruction, anterior ethmoid sinus opacification, posterior ethmoid sinus opacification, frontal sinus opacification, sphenoid sinus opacification, concha bullosa, septal, agger nasi, erosion in lamina papyracea, erosion base of skull, Haller cell, Onodi cell, supra- orbital cell, carotid canal dehiscence, mucocele, abnormal uncinate process were detected. All patients had chest x-ray. All patients were sent for skin prick test. Total IgE was measured for all of them.

Routine investigations were done for all patients who underwent nasal surgery under general anasthesia.

Patients treated medically two week prior to surgery, with:

1. Oral Amoxicillin/clavulanic acid, 40 $\mathrm{mg} / \mathrm{kg} / \mathrm{day}$, (tds). with maximal adult dose of 500/125 amoxicillin/clavulanic acid (tds).

2. Penicillin allergic patients were treated with clarithromycin 250 two times daily.

3. Oral steroid (prednisolone $5 \mathrm{mg}$ tablet) in a dose of $0.5-1 \mathrm{mg} / \mathrm{kg}$ body weight (tds) maximal dose of $60 \mathrm{mg} /$ day (if there is no contraindication).

4. Intranasal steroid: Budesonide (Rhinocort R) for adults and children above 12 years in a dose of 64 micrograms (1 spray) each nostril twice daily.

All patients were underwent endoscopic sinus surgery under general anesthesia. Fifteen minutes before the patient enter the theater, a cotton pledge soaked with $50 / 50$ of $1 \%$ xylometazoline and $2 \%$ lidocain, introduced into nasal cavity. Using rigid Hopkins rod endoscope $\left(0^{\circ}\right.$ and $\left.30^{\circ}\right)$ with camera connected to the monitor, the nasal cavity was examined. Mucin collected initially by large syringe with a suction tube. The inflamed tissue and polyps was removed and collected in a salinemoistened sterile bottle.

By gentle medialization of the middle turbinate, the middle meatus exposure improves. If this was not enough, the tissue on the lateral side of the middle turbinate was removed using tissue shaver.

Next, uncinectomy was performed via an incision with the sharp end of freer elevator or a sickle knife. The incision was placed at the most anterior portion of the uncinate process, which is softer on palpation in comparison to the firmer lacrimal bone, where the nasolacrimal duct is located. Then, a Blakesley forceps is used to grasp the free uncinate edge and remove it. The remaining parts of the uncinate were then removed with great care to avoid unnecessary damage to the mucosa. After that $30^{\circ}$ endoscope is used to identify the maxillary ostium then middle meatal antrostomy was done if required. The ethmoidal bulla was opened, identification of the basal lamella of the middle turbinate and then opening of the posterior ethmoid cells if it was indicated by CT scan. Entering the frontal recess or the sphenoid sinuses was not done unless these sinuses were involved in CT scan. All tissues were removed, kept in $10 \%$ formalin and sent for histopathological examination using H\&E, revealed mucinous background \&often took a chondroid appearance, while eosinophils and Charcot- Leyden crystals are heavily stained and become easily detectable. Histopathological study remains the most reliable indicator of AFRS even better than positive fungal culture as a positive fungal culture does not confirm the diagnosis of AFRS, nor does a negative culture exclude it. For example, fungi may proliferate as saprophytic growth in diseased sinuses. Again, fungal culture was not done in our setting due to the lack of mycology department in the hospital.

\section{Results}

Concerning the age factor which was range from (11-60) years. The highest number with nasal polyposis was seen in patients aged $50-60$ 
years old with mean age (41.3) and SD ( \pm 13.7$)$ (Fig. 1). There were 22 females (36.7\%) and 38 males (63.3\%). The male:female ratio was $1.7: 1$ with nasal polyposis while it was 1.3:1 with rhinosinusitis.
The most common symptom was nasal obstruction (90\%) (fig. 2).

Endoscopically, mucosal congestion is the commonest finding while septal spur is the least presentation $13.3 \%$ (fig. 3).

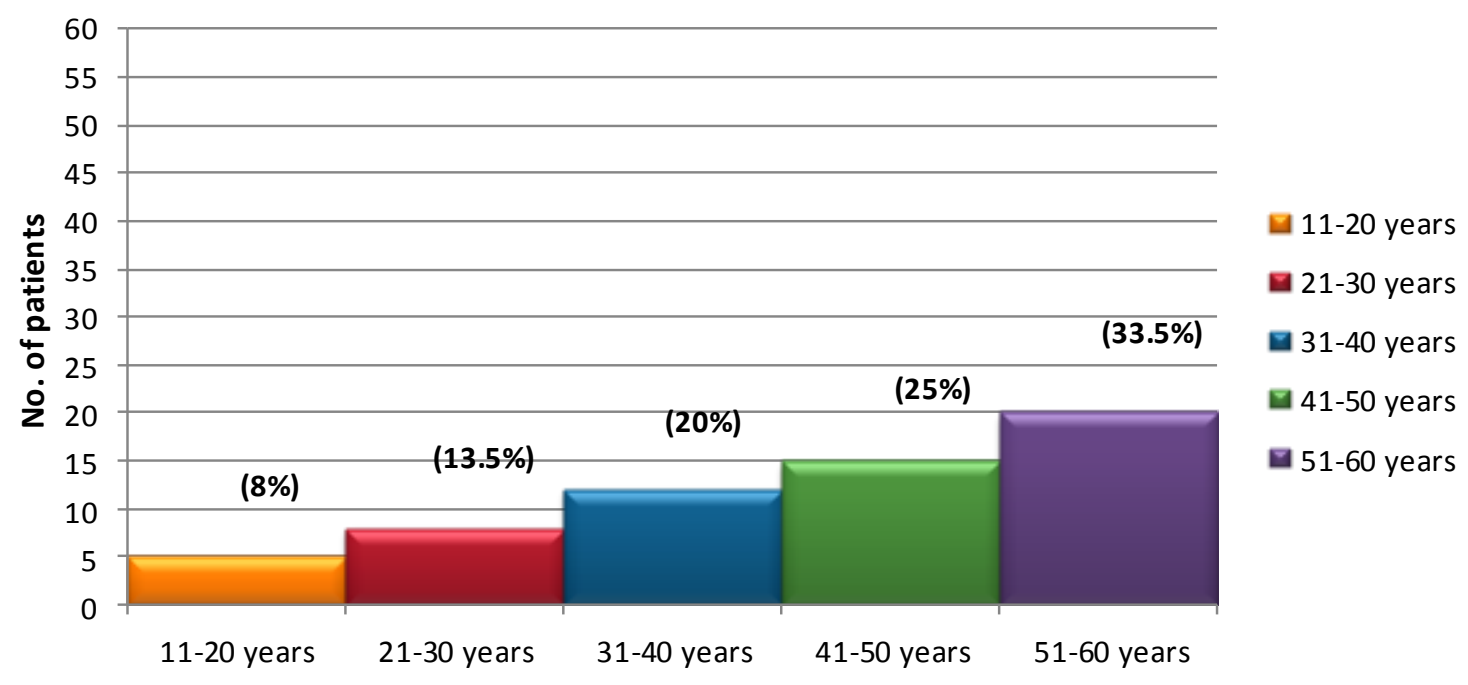

Figure 1. Age distribution in nasal polyposis patients

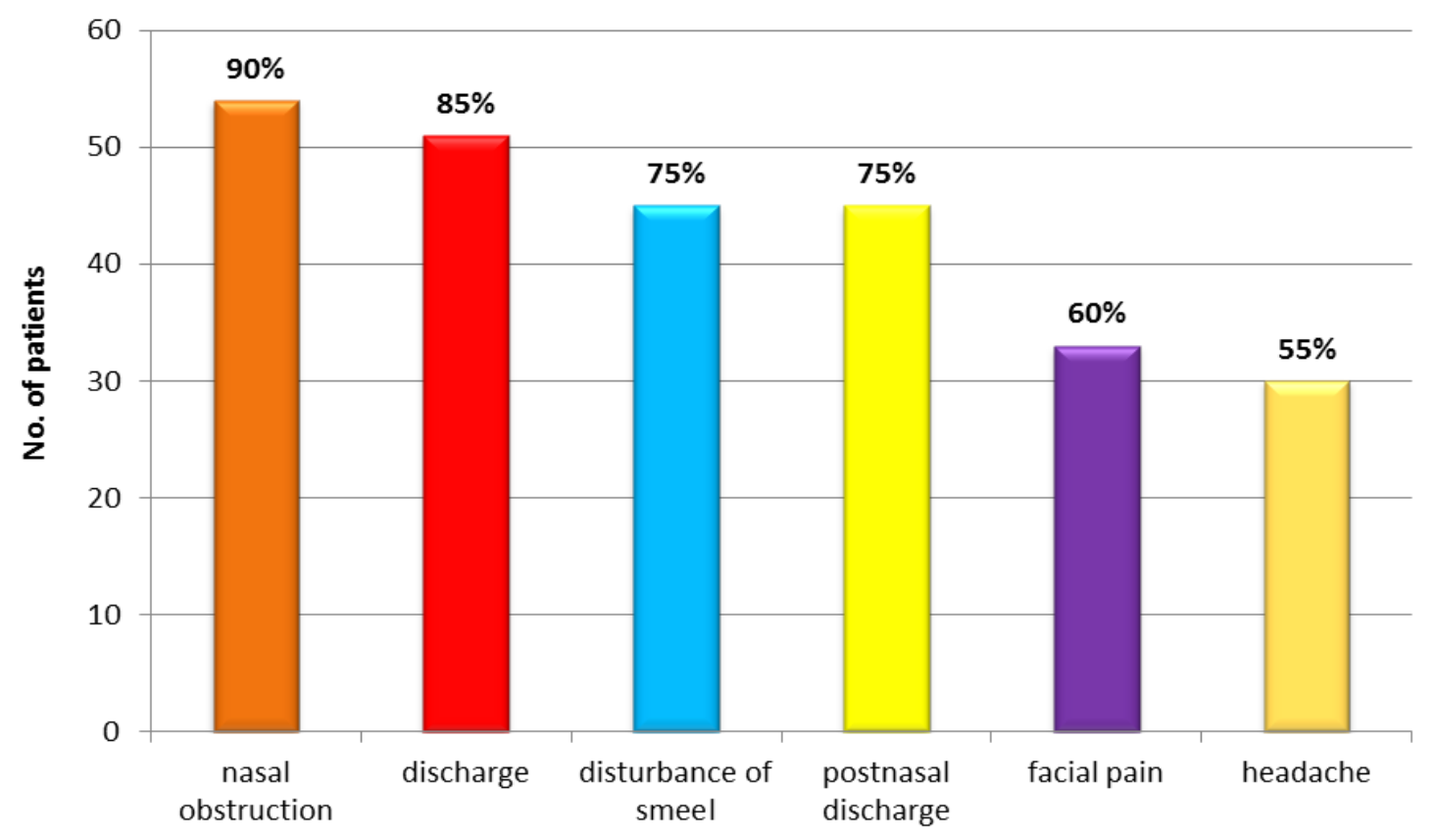

Figure 2. Clinical features of nasal polyposis 


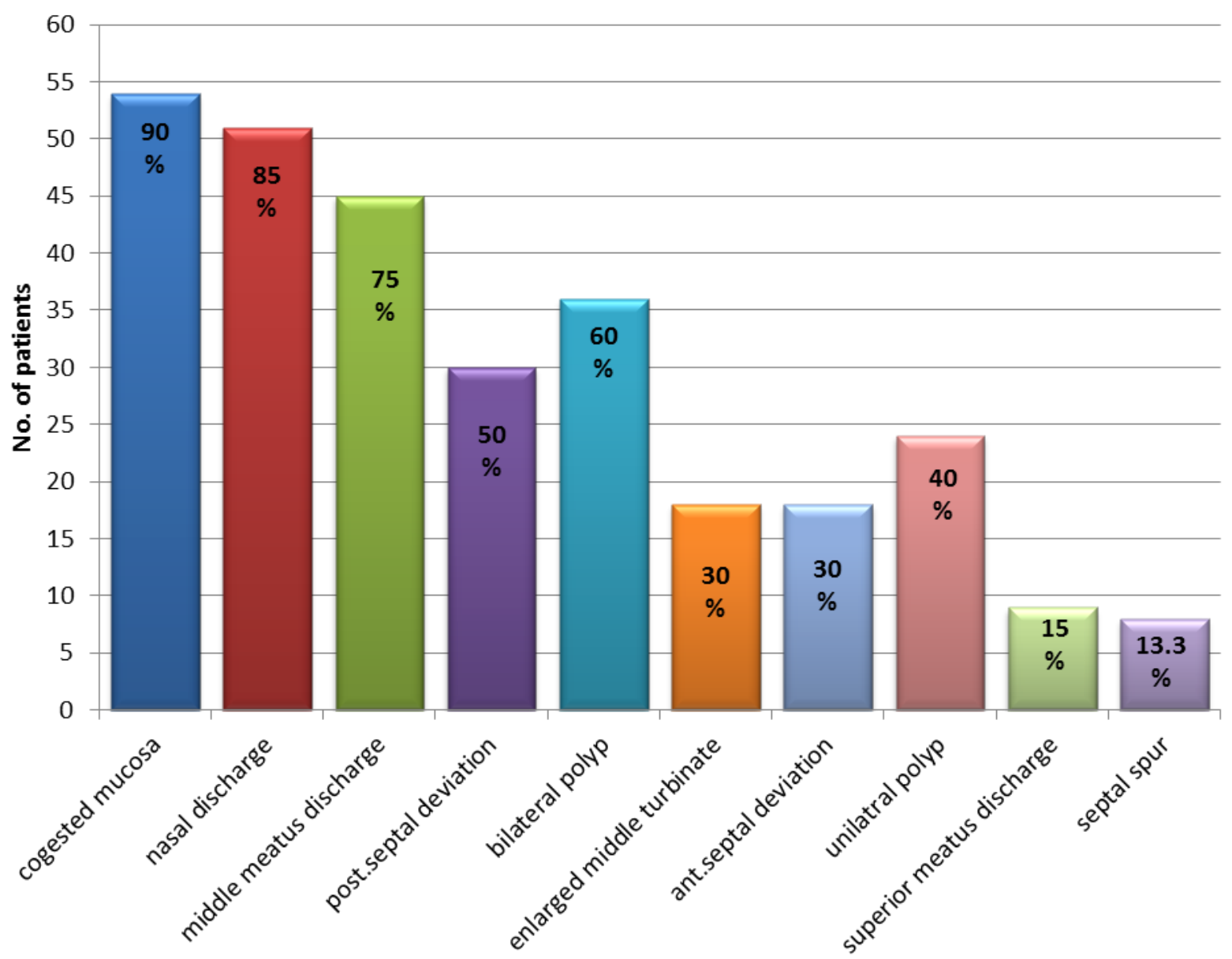

Figure 3. Endoscopic findings

On CT scan, mucosal thickening, osteomeatal complex obstruction and diffuse opacities were found in all cases (100\%). Forty-eight $(80 \%)$ of patients had more than three sinus involvement sites in patients with sinus polyposis (fig. 4), while mucosal thickening with sinus expansion in majority of AFRS patients but the least as bone erosion (fig. 5).

Concerning the laboratory diagnosis, fungal elements were found in 7 patients $(11.7 \%)$ in histological specimens (If sample is positive for fungal element in histopathology, it was considered as positive mycological criteria). Total IgE was elevated in 22 (36.6\%) patients as shown in figure (6).
Total IgE level is statistically not significant for the diagnosis of AFRS ( $P=0.1$ ) (fig. 7).

For histopathological study that is shown in fig. (8), it is of excellent significance statistically in the diagnosis of bilateral nasal polyposis and AFRS $(P=0.007)$, and of no significance with unilateral polyp $(\mathrm{P}=0.1)$.

Only $5 \%$ patients show association of nasal polyposis with Samter's triad (nasal polyposis with aspirin intolerance and asthma) (fig. 9). Therefore; only 7 patients of had findings consistent with AFRS.

The characteristics of patients with AFRS is summarized in table 4. 


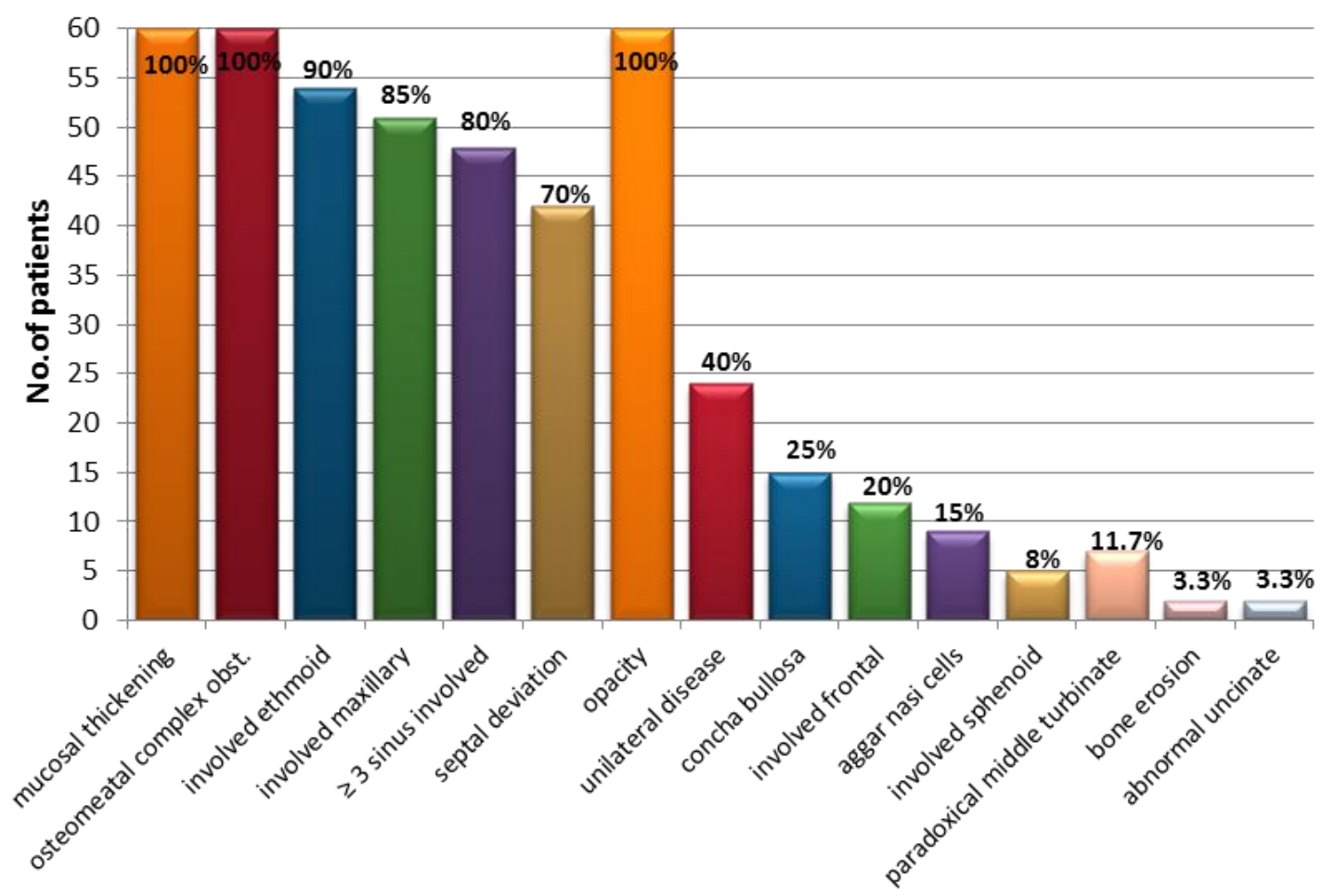

Figure 4. CT findings in nasal polyposis patients

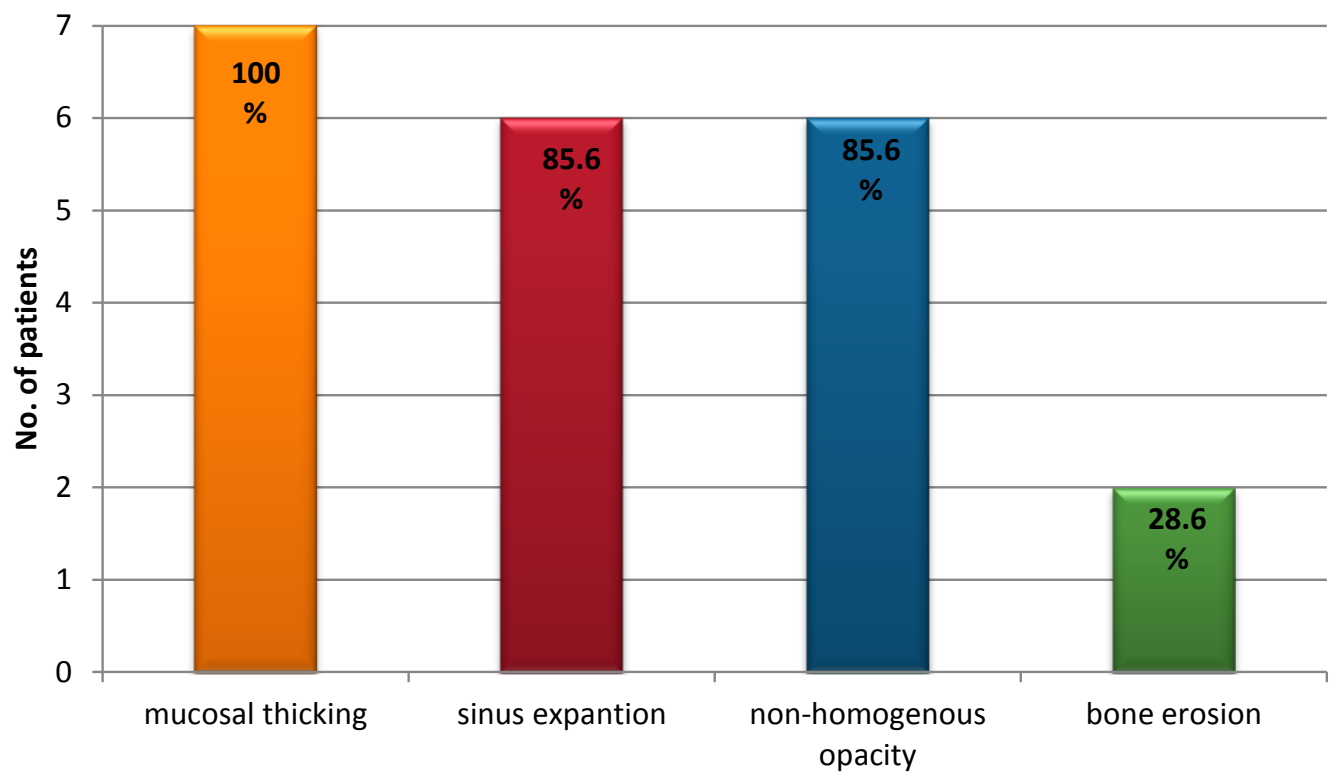

Figure 5. CT findings in AFRS patients 


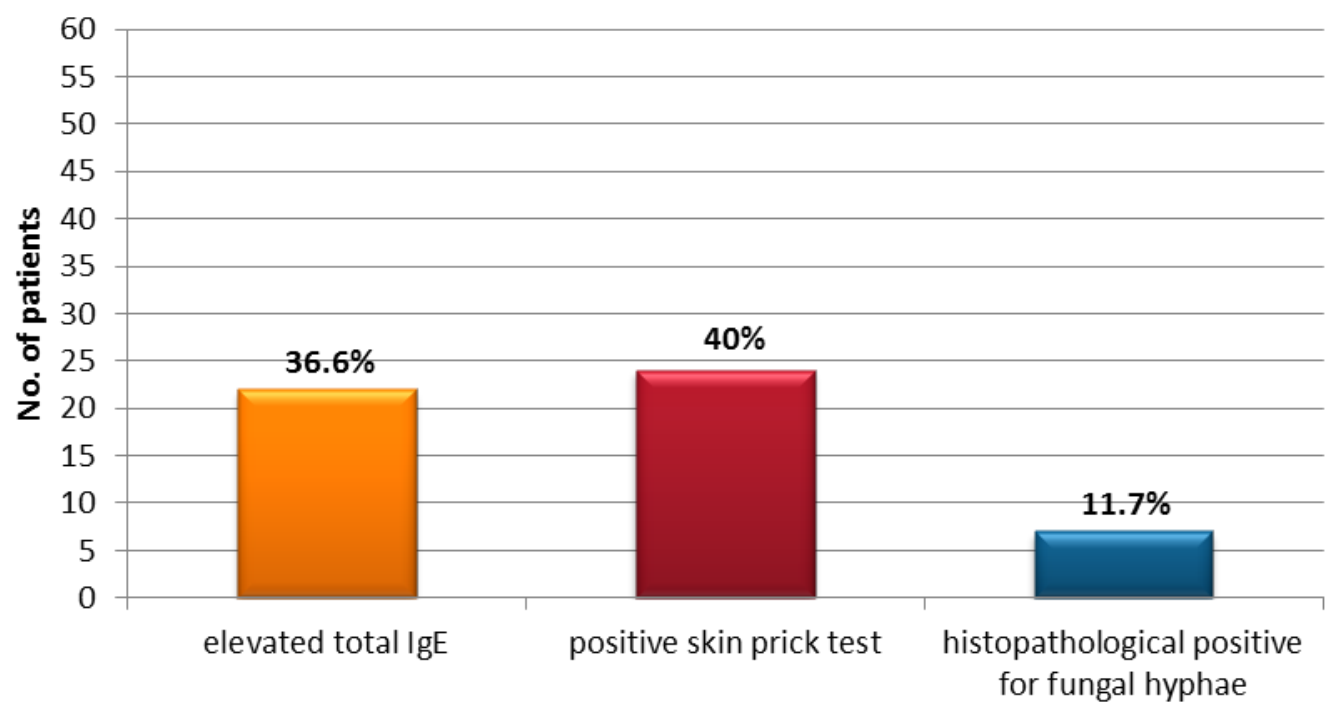

Figure 6. Laboratory findings in nasal polyposis patients

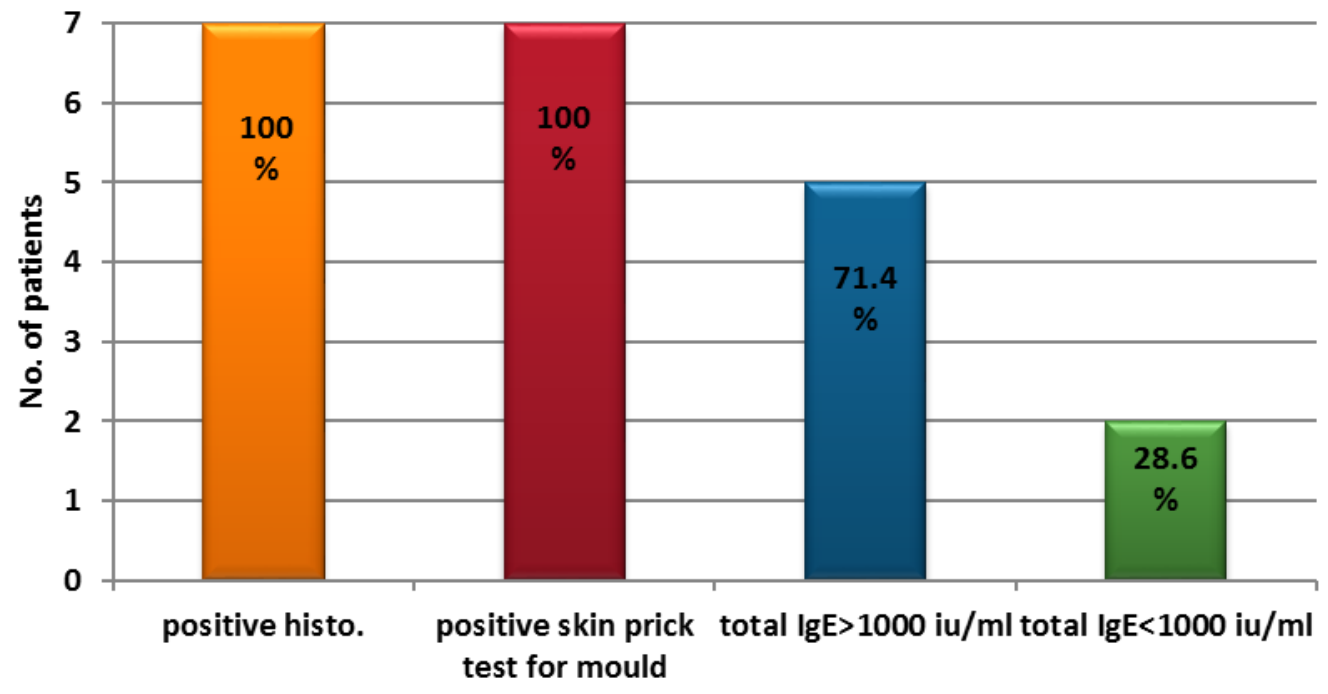

Figure 7. laboratory findings in AFRS patients

\section{Discussion}

All patients in this study were immunocompetent with greatest number of patients with AFRS occur in the $3^{\text {rd }}$ decade of life, which is similar to the findings of Zakirullah et al ${ }^{(3)}$.

In this current study, male:female (M/F) ratio in patients with AFRS is $1.3: 1$, the same male predominance as founded by Thahim et al ${ }^{(4)}$. However, the $M / F$ ratio may be age dependent. A study done on UT Southwestern' children, male predominance were found $(\mathrm{M} / \mathrm{F}$ ratio 2.1:1; average age $=13$ year) while in adults, females were predominant ( $\mathrm{M} / \mathrm{F}$ ratio 1:1.4; average age 36 year) ${ }^{(5)}$.

Nasal obstruction, nasal congestion, nasal discharge and postnasal drip are the major clinical presentation in those patients. Same finding were observed by Hedayati et al ${ }^{(6)}$ and Zakirullah et al ${ }^{(3)}$ who found that $96 \%$ of his patients complain of nasal obstruction. 


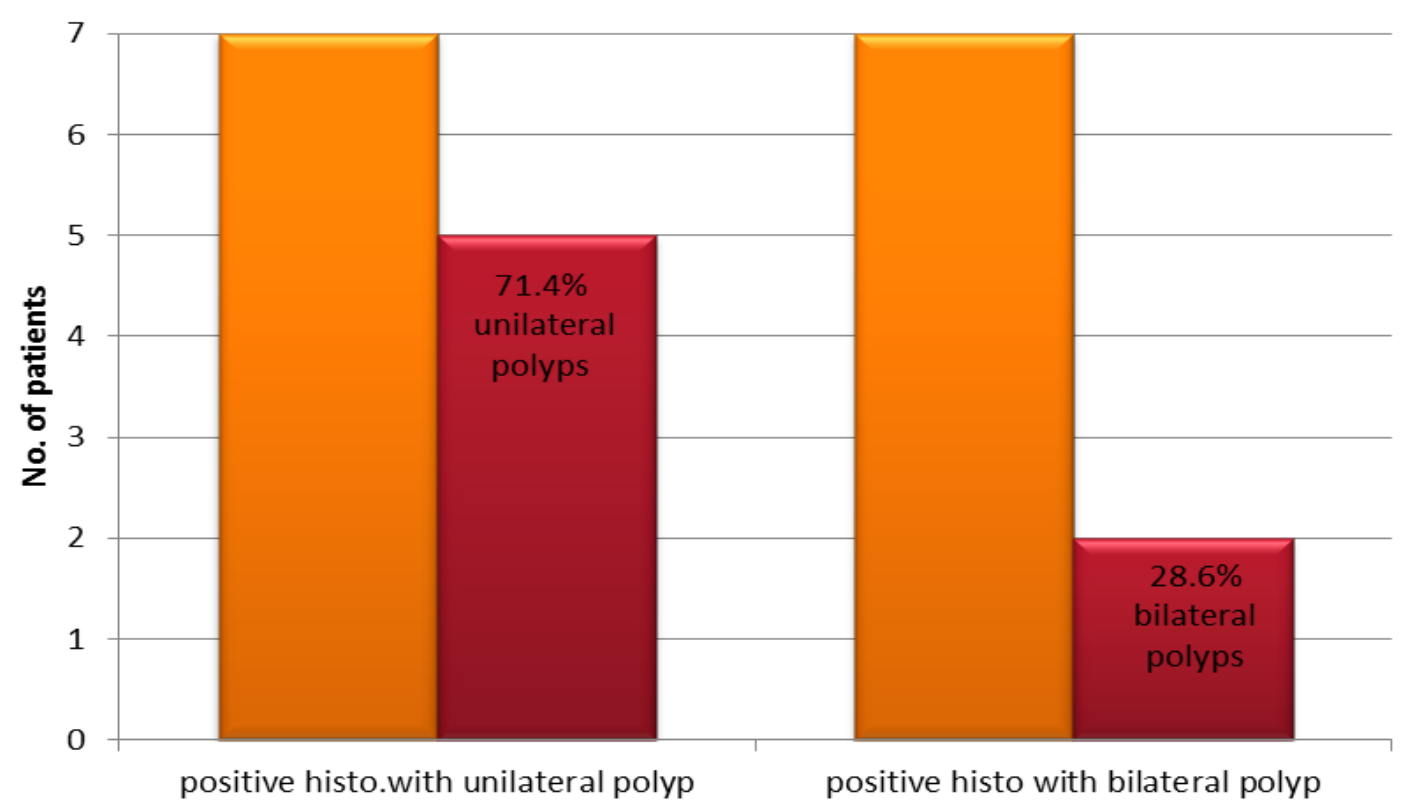

Figure 8. Correlation between positive histopathlogical findings and presence of nasal polyposis

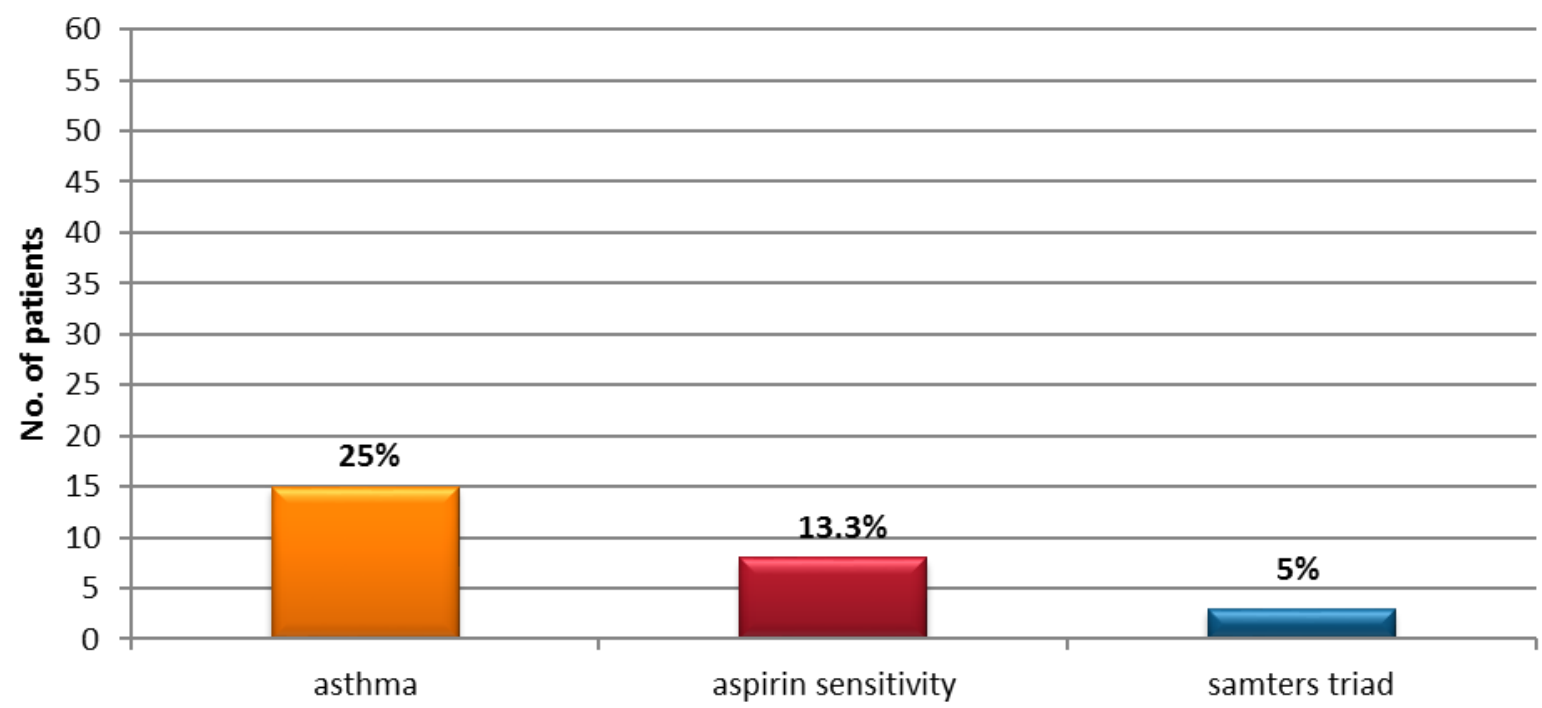

Figure 9. Association between nasal polyposis, asthma and aspirin sensitivity

In the current study, 7 patients had finding consistent with AFRS, the disease was unilateral in 5 (71.4\%) of them and bilateral in $2(28.6 \%)$. Bent and Kuhn ${ }^{(7)}$ and Thahim et al ${ }^{(4)}$ also reported unilateral predominance of the disease. On the other hand, Marple found 51\% bilateral disease in 45 patients ${ }^{(8)}$.

Operative details showed extensive polyposis and characteristic thick peanut-buttery tan to dark-green allergic mucin in all cases. Similar findings are reported by Bent and Kuhn ${ }^{(7)}$ and by Schubert ${ }^{(9)}$. Samter's triad (the association of nasal polyposis, aspirin intolerance and asthma) was found in $5 \%$ of our patients; Kim JE report that $4.8 \%$ of patient undergone functional endoscopic sinus surgery had Samter's triad ${ }^{(10)}$. 
Iraqi JMS 2016; Vol. 14(4)

Table 4: The distribution of patients with allergic fungal rhinosinusitis according to age, sex, site of polyposis \& CT scan findings

\begin{tabular}{|c|c|c|c|c|}
\hline AFRS patients & Number & & Number & $\%$ \\
\hline \multirow{4}{*}{ Age } & \multirow{4}{*}{7} & $2^{\text {nd }}$ decade & 1 & 14.3 \\
\hline & & $3^{\text {rd }}$ decade & 5 & 71.4 \\
\hline & & $4^{\text {th }}$ decade & 1 & 14.3 \\
\hline & & $5^{\text {th }}$ decade & - & - \\
\hline \multirow{2}{*}{ Gender } & \multirow{2}{*}{7} & Female & 3 & 42.9 \\
\hline & & Male & 4 & 57.1 \\
\hline \multirow{2}{*}{ Polyp } & \multirow{2}{*}{7} & Bilateral polyp & 2 & 28.6 \\
\hline & & Unilateral polyp & 5 & 71.4 \\
\hline \multirow{3}{*}{ CT finding } & \multirow{3}{*}{7} & Non-homogenous opacity & 6 & 85.6 \\
\hline & & Bone erosion & 2 & 28.6 \\
\hline & & Mucosal thickening & 7 & 100 \\
\hline
\end{tabular}

Fungal elements were detected by histopathological examination in $7(11.7 \%)$ of our patients, Kupferberg et al found positive histopathological finding in 12.1 of her 91 patients ${ }^{(11)}$.

This variation in the results between the current study and the others may be due to geographic variation in the prevalence of AFRS. The most common CT findings in current study were mucosal thickening and osteomeatal complex obstruction both appeared in all patient $100 \%$. Same findings reported by Mukherji et al (12) who found mucosal thickening in all the 45 studied patients.

Also CT scan showed that unilateral disease was found in 5 of 7 patients diagnosed as having AFRS (71.4\%) and $85.6 \%$ had double density sign, although these findings are not specific for AFRS, they remain relatively characteristic of the disease and may provide preoperative information supportive of a diagnosis of AFRS.

Expansion or thinning of involved sinus walls is common in AFRS and is caused by the expansible nature of the accumulating mucin and polyps.

Bone erosion found in 2 (3.3\%) of patients. Bakhshaee et al ${ }^{(13)}$ found 2 (5.26\%) of his 60 patients were with bone erosion, this actually not due to direct invasion by the fungus but it results from long standing pressure by polyps and accumulation of mucin on the adjacent bone.

Other laboratory investigations showed increased level of total IgE in 22 cases, however, not all of them were diagnosed as having AFRS because other immune mediated conditions are associated with high level of IgE e.g. allergic rhinitis. These results are matching with the reports of Schubert ${ }^{(14)}$.

Total IgE values generally were elevated in AFRS, often to more than $1,000 \mathrm{IU} / \mathrm{mL}$. Total IgE level traditionally has been used to monitor the clinical activity of allergic bronchopulmonary fungal disease. On the basis of similar IgE behavior associated with recurrence of AFRS, and therefore; it is proposed as a useful indicator of AFRS clinical activity, Schubert ${ }^{(14)}$.

Thus, it can be concluded that AFRS is a significant cause of nasal polyposis. It is recommended that all patients with nasal polyposis biopsy should be taken and send for histopathology because AFRS is significant cause of nasal polyposis. Further studies should be done to detect the causative agents, the level of genu species, fungi, by doing culture method.

\section{Acknowledgement}

Grateful thanks to all whom helping and supporting us to finish this paper 


\section{Author Contribution}

All results were collected by the three authors, reviewed and written by Dr Al-hassani.

\section{Conflict of interest}

No publication conflict of interest

\section{Funding}

This study was funded by the Iraqi Board for Otorhinolaryngology Specialization.

\section{References}

1. Mygind $N$, Lund VJ. Nasal polyposis. Gleeson $M$, Browning GG, Burton MJ, et al. (eds). Scott-Brown's Otorhinolaryngology head and neck surgery. $7^{\text {th }}$ ed. London: Hodder Arnold; 2008. p. 1552-3.

2. DeShazo RD, Chapin K, Swain RE. Fungal sinusitis. N Engl J Med. 1997; 337: 254-9.

3. Zakirullah MK, Nawaz G, Sattar SF. Presentation and diagnosis of allergic fungal sinusitis. J Ayub Med Coll Abbottabad. 2010; 22(1): 53-7.

4. Thahim K, Jawaid MA, Marfani MS. Presentation and management of allergic fungal sinusitis. J Coll Physicians Surg Pak. 2007; 17: 23-7.

5. Schubert MS. A superantigen hypothesis for the pathogenesis of chronic hypertrophic rhinosinusitis, allergic fungal sinusitis, and related disorders. Ann Allergy Asthma Immunol. 2001; 87(3): 181-8.

6. Hedayati MT, Bahoosh M, Kasiri A, et al. Prevalence of fungal rhinosinusitis among patients with chronic rhinosinusitis from Iran. J de Mycologie Médicale. 2010; 20: 298-303.

7. Bent JP $3^{\text {rd }}$, Kuhn FA. Diagnosis of allergic fungal sinusitis. Otolaryngol Head Neck Surg. 1994; 111(5): 580-8.

8. Marple BF, Mabry RL. Allergic fungal sinusitis: Learning from our failures. Am J Rhinol. 2000; 14: 223-6.

9. Schubert MS. Allergic fungal sinusitis. Otolaryngol Clin North Am. 2004; 37(2): 301-26.

10. Kim JE, Kountakis SE. The prevalence of Samter's triad in patients undergoing functional endoscopic sinus surgery. Ear Nose Throat J. 2007; 86(7): 396-9.

11. Kupferberg SB, Bent JP, Kuhn FA. Prognosis for allergic fungal sinusitis. Otolaryngol Head Neck Surg. 1996, 117: 35-41.

12. Mukherji SK, Figueroa RF, Ginsberge LE, et al. Allergic fungal sinusitis: CT findings. Radiology. 1998; 207: 417-22.

13. Bakhshaee $M$, Feredouni $M$, Mohajer $M N$ et al. Prevalence of allergic fungal sinusitis in sinonasal polyposis. Eur Arch Otol Rhinol Laryngol. 2013; 270(12): 3095-8.

14. Schubert MS, Goetz DW. Evaluation and treatment of allergic fungal sinusitis. II Treatment and follow-up. J Allergy Clin Immunol. 1998; 102(3): 395-402.

\footnotetext{
Corresponding to Jaafer M. K. Al-Hassani E-mail: j_m_k65@yahoo.com

Received: $9^{\text {th }}$ Dec. 2015, Accepted: $27^{\text {th }}$ Nov. 2016
} 